\title{
¿El sentido del humor, tiene sentido en el aula?
}

\section{Does Sense of the Humor Make Sense in the Classroom?}

\author{
Freddy Antonio González Ynfante ${ }^{l}$ \\ Distrito Escolar Maturín \\ Zona Educativa Monagas \\ Venezuela \\ freddyagy@yahoo.com.ve
}

Recibido 09 de junio de 2011 • Aceptado 24 de octubre de 2011

\begin{abstract}
Resumen. El presente ensayo tiene como finalidad reflexionar sobre la importancia del humor pedagógico como estrategia de enseñanza aprendizaje en el aula; esto, tomando en cuenta la problemática de desmotivación y aburrimiento que sucede normalmente en la clase. Para plantear si "el enseñar contento y el aprender con alegría" pueden aumentar la eficacia en el proceso de enseñanza-aprendizaje, se abordará cómo, a pesar de las múltiples ventajas que puede aportar el humor en las aulas, se omite su empleo por la existencia de ciertos prejuicios y temores. La idea no es que los docentes hagan el papel de comediantes o payasos, sino la de mediar y acercar la clase de manera pedagógica y didáctica a través del uso del humor, y sobre esto reflexionaba Platón (1992), cuando planteaba que muchas veces ayudaba una broma, en donde la seriedad oponía resistencia.
\end{abstract}

Palabras claves. Humor, motivación, estrategias, enseñanza, aprendizaje.

Abstract. This paper studies the importance of humor as a teaching strategy in the classroom, considering the usual lack of motivation and boredom. To analyze whether the "happy teaching and happy learning" may increase effectiveness in the teaching-learning process, the author will discuss how, despite the many benefits it may bring, humor is not used in the classroom due to prejudices and fears. The idea is not for teachers to play the role of a comedian or a clown, but to intervene and get closer to the group with a teaching, didactic purpose through humor. Plato (1992) thought about this; he used to say that sometimes a joke may help, where seriousness put up resistance.

Keywords. Humor, motivation, strategies, teaching, learning.

“...Vamo” a reír un poco...

Esta risa no es de loco...

Héctor Lavoe, cantante

\section{Introducción}

¿Por qué escribimos tan poco sobre el humor y la risa en el campo de la Pedagogía y la Educación? Poco se escribe y se reivindica el humor y la risa que se mete de manera irreverente, en el dominio de lo que llamamos "serio", que a decir de Larrosa (2002, p.171) "esa risa que se ríe precisamente de aquello que la pedagogía marca como no risible”. Ahora, ¿es posible ver las

\footnotetext{
Profesor en Educación Agropecuaria. Especialista en Procesos Didácticos a Nivel Educativo Básico.
} 
situaciones o acontecimientos más serios con sentido del humor? Para saber si tales interrogantes merecen una respuesta, conviene allanar el camino con algunas ideas y ejemplos, en este caso, se hace referencia a la penosa situación de Tomás Moro (citado en González 2009. p. 5) cuando “(...) era conducido al patíbulo (en 1535) para su ejecución y que al llegar a las escaleras, dijo al verdugo: 'Ayúdame a subir hijo, que para bajar ya me arreglo solo!' (...)”. De acuerdo con Martin (2003), el humor permite mitigar los problemas y las desgracias que se presentan en la vida.

Al entrar en el ámbito científico del humorismo, sorprende que este fenómeno haya despertado tan poco interés entre los investigadores de la Educación. Extraña que esta actitud se mantenga además en las aulas por parte del profesorado, pues estoy convencido de que los docentes, a la hora de impartir las asignaturas, buscamos cualquier mecanismo que mejore la manera de enseñar a los estudiantes. El humor, normalmente, es censurado por las instituciones educativas, la razón estriba, si seguimos el argumento de Umberto Eco en su obra narrativa "El nombre de la rosa", en que el humor, la risa, la comedia, atentan las estructuras que conforman dichas instituciones, ya que estos elementos buscan transgredir, descalificar, desliteralizar, ir de lo superior a lo inferior, enlazarse con la cotidianeidad y romper los ideales, o desarrollar parodias o burlas a las autoridades. Entonces, en una institución escolar en donde es interesante el sentido del humor, ¿ya no tiene sentido? Tal vez haya de ser así, para los que hacen separaciones entre lo serio y divertido, o los que hacen separaciones entre el mundo adulto e infantil. Decía Pepe Viyuela que los niños suelen reír mucho y no les confiamos tareas 'serias' hasta que no han empezado a crecer y ya los hemos mutilado lo suficiente de su capacidad para ser frescos y espontáneos, como para poder confiarles esas 'responsabilidades' de adultos. Es, entonces, cuando creemos que podemos confiar en ellos, cuando la domesticación social los ha llevado a parecerse al resto de la sociedad adulta. Tal vez olvidamos que no hay mundo adulto sin mundo infantil, que construimos el mundo adulto, el propio, cuando somos niños y niñas, que construimos mundo adulto, el social y general, cuando nos relacionamos, de una manera o de otra, con los niños y niñas de hoy. Tal vez olvidamos que, en mucho de lo que este proceso mutila, podrían estar las claves de una nueva persona, de esa que ansiamos tantos, y que todavía hoy es tan urgente. Este artículo tiene como intención reflexionar sobre la importancia del humor pedagógico como estrategia de enseñanza y aprendizaje en el aula, tomando en cuenta la problemática de desmotivación y aburrimiento que normalmente suceden en el aula.

\section{Intentar definir el humor para darle sentido en el aula}

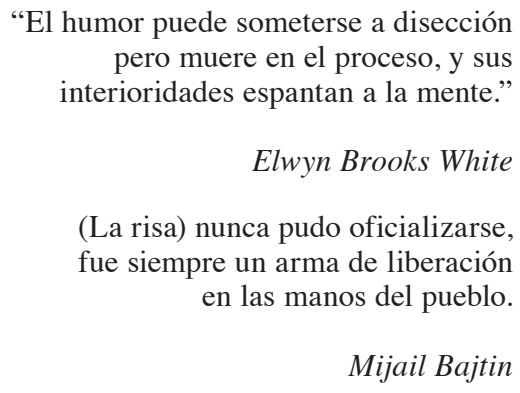

Cabe aclarar que intentar definir el humor o la risa ya es cómico en sí mismo, es creer que existe en el lenguaje la posibilidad de la definición precisa. Por eso, intentar explicar un chiste es destrozarlo. En la actualidad todavía no existe un modelo que ajuste completamente el sentido del humor. Aunque se han buscado explicaciones y definiciones, ninguna es completamente satisfactoria 
y los modelos que más convencen se han respetado durante años. Decía Poncela (citado en Acevedo, 1972), que intentar definir el humor es como pretender pinchar una mariposa usando, a manera de alfiler un poste de telégrafo. Así pues, dadas las dificultades para establecer su estatuto ontológico, me aproximaré al humor partiendo de algunas definiciones o ideas que he recogido relacionadas con el ámbito de la experiencia de investigación sobre el tema. Garanto (1983) expone que:

El humor es el estado de ánimo más o menos persistente y estable, que baña equilibradamente sentimientos, emociones, estados de ánimo o corporales, surgentes del contacto del individuo (corporalidad y psique) con el medio ambiente y que capacita al individuo para, tomando la distancia conveniente, relativizar críticamente toda clase de experiencias afectivas que se polaricen, bien sea hacia situaciones eufóricas, bien sea hacia situaciones depresivas. (p. 61)

Así mismo, Gubern (citado en Medina, 1992, p. 40), concibe el humor desde la óptica Freudiana como “(...) un medio para reconciliar el principio del placer y el principio de la realidad, cumpliendo en la imaginación aquellos deseos frustrados en la vida real (...). Por otro lado, Fernández (citado por Vigara, 1994) expone que el humor es simplemente una posición ante la vida, que va a permitir al individuo disfrutar, en menor o mayor grado, lo relativo de las cosas que se consideran absolutas o no ante el mundo. En esa misma línea, Artalejos (citado por Torres, 2006) considera el humor como una actitud humana, un asumir una posición ante la realidad que se vive. Y para Checa (1992) es un proceso social y cultural que puede emplearse de manera individual o colectiva, y que contiene una enorme fuerza para provocar cambios de actitud.

\section{Teorías que sustentan el humor}

Desde los inicios de la filosofía occidental, los filósofos trataron de explicar la naturaleza del humor. Podemos distinguir tres teorías fundamentales: la teoría de la superioridad, la teoría de la incongruencia y la teoría de la descarga o tensión.

\section{Teoría de la superioridad}

Desde la óptica de los antiguos filósofos, la risa era inmoral y arrogante; principalmente uno de ellos, Platón, en su Filebos (1992), planteaba que al descubrirse un vicio o desgracia en una persona y reírnos de eso con sarcasmo o burla, provocaba en el otro una reacción violenta. Aristóteles en su Poética (1988) planteaba que el reírse de otro afianzaba el yo de manera orgullosa, y se arrogaba superioridad. Por su parte, Hobbes (1993) plantea lo contrario de lo expuesto y lo lleva al plano de lo pusilánime, afirmando que es tarea de las grandes mentes conscientes el de ayudar a los otros a superar los temores, vicios, errores o defectos y no reírse de su desdicha. Para uno de los autores de esta teoría de la superioridad, el filósofo francés Bergson (1986, p. 107), la comicidad “(...) expresa (...) cierta imperfección individual o colectiva que exige una corrección inmediata (...)”, en opinión de este autor en tal imperfección no hay compasión ni oportunidad, sino el disfrute de corrección y castigo. De allí su planteamiento sobre cómo la comicidad atenta contra la vida de la colectividad. 
En el marco de esta teoría puede interpretarse el siguiente ejemplo:

- En un restaurante;

"[Cliente] A: ¡Mesonero, este pan está blando!.

[Mesonero] B: Pues, ¡dígale que se calle!” (Cortés, 1994, p. 292)

En el ejemplo anterior podemos observar en el cliente una velada intención de ejercer superioridad (para ser atendido) hacia el mesonero, la cual se ve empañada ante la respuesta que emite el mesonero. Esta respuesta es lo cómico que hace fracasar las pretensiones del cliente.

\section{Teoría de la incongruencia}

Esta teoría plantea que lo que genera risa son las incongruencias de situaciones que entran en cierta contradicción o están apoyadas por ideas bastante diferentes, por ejemplo en aquellas situaciones que se está esperando algo y surge otra completamente diferente, esa sorpresa es lo cómico que causa la risa. Schopenhauer (1996, p. 68), uno de los exponentes de esta teoría, explica que "la causa de lo risible, está siempre en la subsunción o inclusión paradójica, y por tanto inesperada, de una cosa en un concepto que no le corresponde, y la risa indica que de repente se advierte la incongruencia entre dicho concepto y la cosa pensada, es decir, entre la abstracción y la intuición. Cuanto mayor sea esa incompatibilidad y más inesperada en la concepción del que ríe, tanto más intensa será la risa". Para Schaeffer (1981, p. 27) "la risa o el placer asociado a la risa es el resultado de la percepción de una incongruencia en un contexto lúdico, esto es, un contexto basado en la ausencia de racionalidad". De acuerdo con lo anterior, el humor implica distorsión de la realidad, romper con lo establecido, y esa incongruencia es la que nos llama la atención, nos asombra y nos despierta el humor, nos hace reír o sonreír. Aunque existen numerosos ejemplos, veamos una anécdota respecto a una serie de preguntas extraídas de la realidad y realizadas por algunos profesionales:

(...) Usted estuvo allí hasta que se marchó, ¿no es cierto? (Humor, párr. 8)

Pregunta: "Ella tuvo tres hijos ¿cierto?"

Respuesta: "Sí"

Pregunta: “¿Cuántos fueron varones?”

Respuesta: "Ninguno"

Pregunta: “¿Hubo alguna mujer?” (Humor, párr. 11)

Pregunta: "Doctor ¿cuántas autopsias ha realizado usted sobre personas fallecidas?"

Respuesta: "Todas mis autopsias las realice sobre personas fallecidas”. (Humor, párr. 17)

Observando los ejemplos, se denota lo incongruente de las preguntas con las respuestas en cada caso. Es inconcebible que haga preguntas incongruentes quien se supone que debe saber formularlas para precisar la situación. Son sorpresivas e inesperadas, por eso causan gracias, porque la persona abordada no espera que un profesional cometa errores incoherentes, propios de su perfil. 


\section{Teoría de la tensión o descarga}

Esta teoría despeja algunos vacíos o lagunas que la teoría de la superioridad y de la incongruencia había dejado. Fue expuesta por Spencer (1860), quien describió el humor en términos de alivio físico, en contradicción con otros autores quienes sostenían que la liberación de la tensión no es más que liberar las emociones. Según este autor, los individuos actúan sometidos al esfuerzo, la lucha y tensión, descargadas a través del sistema nervioso (excitado) hacia las diferentes estructuras del organismo para mantener un equilibrio. Así actúa la risa, proporcionando un equilibrio y alivio para la tensión nerviosa o psíquica. Un ejemplo es el siguiente:

En una audición de música, en el silencio del teatro, se escucha un estornudo; la intensidad de la atención puesta en la escucha y lo inesperado del estornudo hacen que decaiga rápidamente la atención, pudiendo alguien descargar la tensión por medio de la risa. Muchas personas han experimentado este ejemplo en otras circunstancias más serias como los velatorios o funerales porque, además, la expresión del humor en estas circunstancias supone un alivio o bálsamo ante la situación. (Carbelo, 2005, p. 28)

En el anterior ejemplo, se puede observar que mientras más tensión exista, un inusual motivo, una expresión, un ruido o una broma pueden aliviar la tensión de un acontecimiento, desencadenando la risa o la sonrisa como una forma de descarga y alivio.

\section{El humor en la praxis pedagógica}

Podemos escuchar, con una frecuencia mayor de lo deseado, frases del tipo "No es la hora de reír, ahora hay que ponerse serios", que se dirigen al estudiantado, desde el subsistema de educación inicial. Comentarios que inconscientemente se hacen, sin reflexionar en la trascendencia que pueden tener, influenciados, en parte, por la consideración social que existe sobre el humor. El cual es entendido, a menudo, como sinónimo de inmadurez, como pérdida de tiempo o como falta de seriedad y de eficacia. Ahora, pregunto: ¿Se puede enseñar con humor? Con esta interrogante, me encuentro en el mismo dilema que tenía Sócrates, cuando se preguntaba si se podían o no enseñar las virtudes. De todos modos, de una cosa sí estoy convencido, de que necesitamos en nuestro sistema educativo más humor en nuestra praxis pedagógica, y en esto me apoya Burguess (2003) en su libro Escuelas que ríen, el cual considera fundamental ayudar a los maestros a comprender la importancia de crear un ambiente agradable en el que reine el buen humor; convencerlos de que la risa puede ser un elemento esencial para el aprendizaje; ayudarlos a sacar provecho del aspecto cómico que ya existe en clases y mostrarles maneras de combinar la risa con el aprendizaje, pues, a decir de Kant (1981), no nos reímos de algo o de alguien sino con algo o alguien. Y ese algo y ese alguien son la clase y el docente con quien nos divertimos. Decía Pike (1999), el aprendizaje es directamente proporcional a la cantidad de diversión que se tiene, lo cual se traduce en que, si el estudiante se divierte mientras aprende, aprenderá más efectivamente, es decir, hay que provocar un aprendizaje placentero para que se vuelva a experimentar el placer de aprender. Un buen chiste o una viñeta puede ser una poderosa herramienta para ilustrar un punto cualquiera de un contenido de clase, en este planteamiento me apoyan Snetsinger y Grabowski (1998) quienes plantean que: 
(...) La incorporación de temas y comentarios humorísticos relativos al contenido sirven para crear una atmósfera positiva de aprendizaje, motivando a los estudiantes a atender el material y ayuda a comprender los conceptos y hechos más difíciles, mejor que el material presentado de la forma normal o no- humorística. (p. 373)

El planteamiento anterior expone la importancia de crear una atmósfera positiva en clases, relacionando contenidos con temas humorísticos escritos, verbales o con el uso de viñetas gráficas, ya que según Flores (2003, p. 52) “(...) se hacen precisos puentes para facilitar la comunicación en los sujetos implicados en la enseñanza (...)”. El hacer agradable el ambiente escolar, en donde los estudiantes se sientan bien aprendiendo y divirtiéndose no requiere que el docente haga el papel de payaso o bufón; hay que saber usar el humor en el momento preciso, de lo contrario se puede correr el riesgo de empañar el objetivo principal de la enseñanza y la experiencia de aprendizaje se convertiría en un simple relajo, traducido en indisciplina en el aula. El elemento importante en el aprendizaje es el estudiante y no el profesor. En tal sentido González (2009) expone que:

(...) se necesita de docentes que se adecuen a los nuevos tiempos y asuman lo que necesita el alumno en la actualidad. Esto significa, ayudar a los maestros a revisarse interiormente, a redefinir su vocación, a reflexionar sobre sus prácticas pedagógicas, a documentarse y a tener su mente abierta al mundo que los rodea. (p. 3)

Bien lo decía Safo de Lesbos (citada por González, 2009), poeta griega en uno de sus poemas, que era preferible reír antes que representar una tragedia o melancolía, concibiendo la risa como un escudo ante las adversidades de la vida. De la misma manera, podrían asumir los docentes la postura de Safo a la hora de encontrarse con situaciones de tensión en su praxis pedagógica y decir parafraseando a esta, “(...) la situación es difícil jóvenes, o ustedes me entienden o nos aburrimos todos. Para evitar ambas cosas vamos a reírnos para entendernos en clases” (González, 2009, p. 5). ¡Vamos a reír para entendernos en clases! Quizás esa sea una de las claves de la estrategia del docente, o como lo decía el Zaratustra de Nietzsche (1883/1885): “(...) Yo he santificado el reír, vosotros, hombres superiores, aprendedme - ¡A reír!” (p. 193).

\section{El humor de antes quería hacer reír, hoy quiere hacer pensar}

"El humor motiva una reflexión, la comicidad te hace cosquillas"

Roberto Malaver Humorista venezolano

La aplicación didáctica del humor pedagógico en el aula se puede centrar en dos aspectos: el uso de viñetas (humor gráfico) y la utilización del humor escrito y verbal (chiste). A continuación se explica la metodología: 


\section{- Uso de viñetas gráficas:}

El empleo del humor gráfico a través de viñetas en el tratamiento de temas educativos constituye una vía pedagógica alternativa que provoca la reflexión y promueve una mejor comprensión de los mismos, al tiempo que hace sonreír. Existe una predisposición positiva en el ser humano hacia la risa, hacia lo cómico, hacia el humor. Reírse de situaciones que reflejan la realidad cotidiana, ridiculizándola o exagerándola, es algo natural, propio de los individuos. La viñeta (figura 1) que se expone a continuación se centra en las largas listas de espera de los pacientes, quienes generalmente aguardan para ser operados en algunos hospitales y clínicas. La frase del médico: "Ha tenido usted suerte, para aliviar las listas de espera, le va a operar el gerente", resume en primer lugar tensión por la evidencia de la cantidad de tiempo de espera por parte del paciente para ser operado, y segundo, más tensión por el hecho de que pueda operar el gerente, más preparado para otras tareas administrativas.

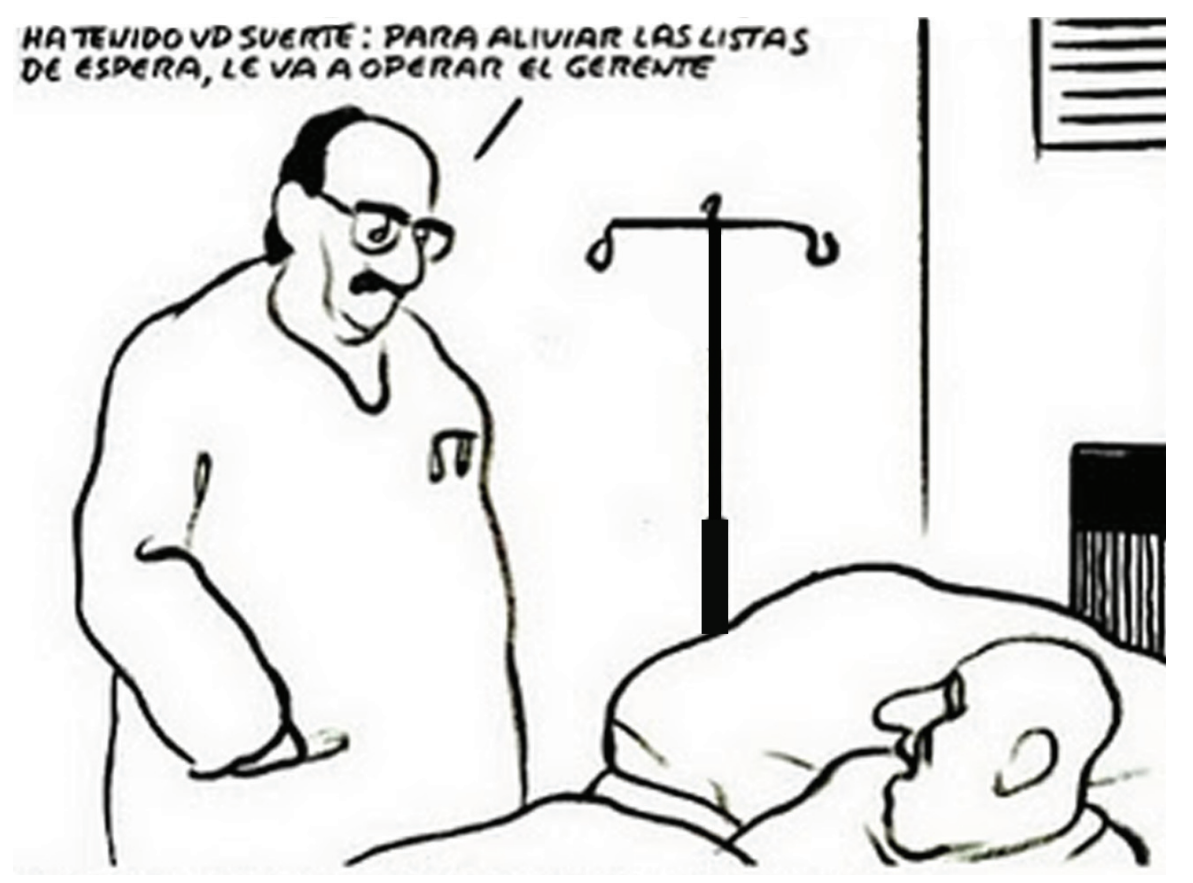

Figura 1: Viñeta de EL ROTO (2000) ${ }^{2}$

Cuando se produce una contradicción, un choque entre la realidad y el ideal que manejábamos de esta, y triunfa o se exalta el ideal, ridiculizando para ello la realidad, burlándola, haciéndola risible, nos encontramos en presencia de lo cómico. Como fenómeno antropológico, lo cómico entra dentro del terreno del juego (homo ludens), al gusto del hombre por la broma y el chiste, a su

La publicación de la figura 1 es propiedad del caricaturista El Roto (Andrés Rábago), el autor del artículo aportó el permiso que se encuentra en los archivos de la Revista electrónica Educare y que fue comunicado mediante correo electrónico de 30 de septiembre de 2011 (elroto. elpais@gmail.com) 


\section{URL: http://www.una.ac.cr/educare}

facultad de imaginar aspectos insólitos y ridículos de la realidad física y social. Dentro del aspecto social, ofrece los medios para criticar al entorno, para ocultar su oposición a través del ingenio o de una ironía. Al humor no le interesa la hilaridad, sino más bien una risa o sonrisa reflexiva. La viñeta (figura 2) sobre el tema del hambre y las Cumbres Mundiales de Alimentación, ilustra la idea antes expresada.

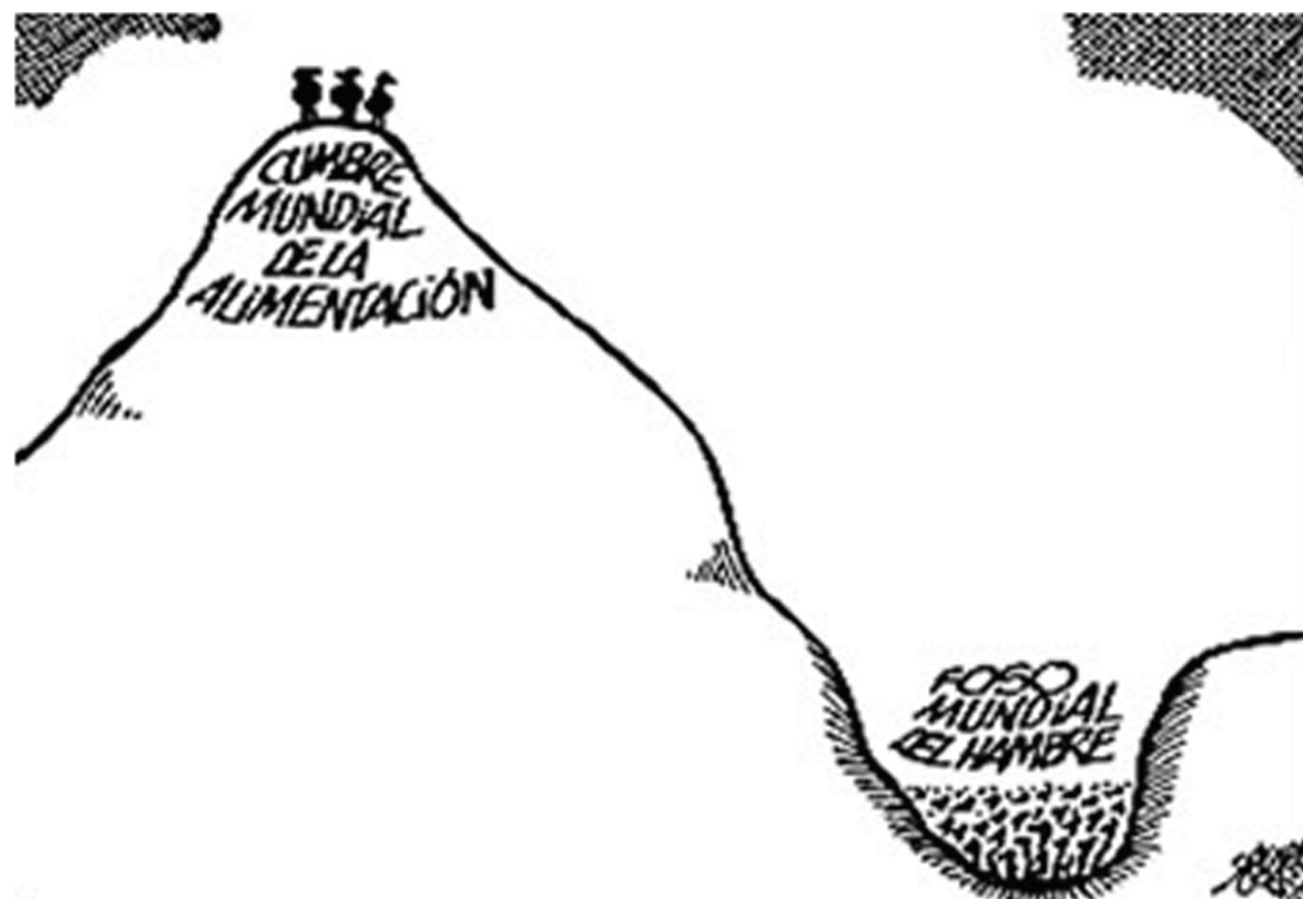

Figura 2. Viñeta que ilustra sobre el tema del hambre y las Cumbres Mundiales de Alimentación. Fraguas-Forges (s. f.) ${ }^{3}$

El humor, el chiste o lo cómico, es una vía que los seres humanos tienen para relajar sus tensiones, hacer catarsis y además, entretenerse. Pero también puede servir para transmitir ideas de una manera diferente, de modo que estas sean aceptadas y entendidas por el colectivo. Visto de este modo, el humor se convierte en una herramienta comunicativa y pedagógica que puede desempeñar un importante rol en la creación de una cultura acerca del ambiente y lo ecológico.

La publicación de la figura 2 es propiedad del caricaturista español Forges (Antonio Fraguas), el autor del artículo aportó el permiso que se encuentra en los archivos de la Revista Electrónica Educare y que fue comunicado mediante correo electrónico de 30 de septiembre de 2011 (antoniofraguasfoges@gmail.com) 
La siguiente viñeta (figura 3) es un ejemplo de lo explicado, y está referida al calentamiento global (Global Warming) en donde se invita al lector a reflexionar sobre la forma irracional de cómo a través del mal llamado "desarrollo" estamos contaminando y destruyendo el planeta.

\section{GLOBAL WARMING}

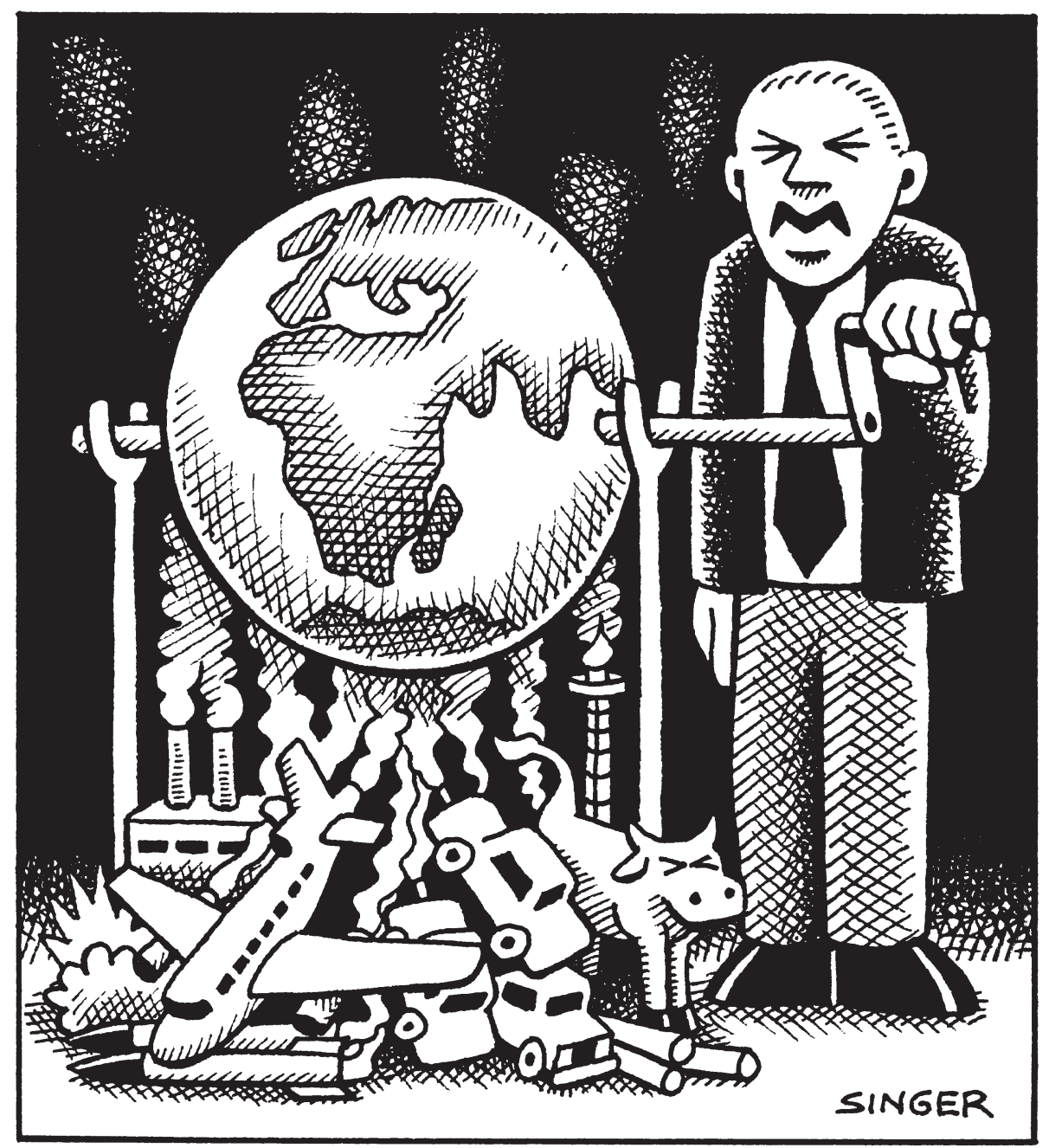

Figura 3. Viñeta No Exist Global Warming (Singer, 2009)4.

Grosso modo, el humor no persigue solamente la distracción o el placer del público. Detrás de su aparente sencillez evoca una reflexión, a veces amarga sobre la vida misma, lo cual deja en el espectador una inclinación hacia la toma de conciencia ante lo reflejado. Decía Jankelevitch (1983, p. 150), el humor es: "la sonrisa de la razón (...)".

\footnotetext{
La publicación de la figura 3 Global Warming, es propiedad del autor Andy Singer, el autor del artículo aportó el permiso que se encuentra en los archivos de la Revista Electrónica Educare y que fue comunicado mediante correo electrónico de 30 de septiembre de 2011 (andy@ andysinger.com).
} 


\section{- Utilización del humor escrito y verbal (chiste)}

De manera espontánea o intencional podemos utilizar el humor verbal o escrito a través del chiste en situaciones en donde la praxis educativa lo amerite. Según Lipps (1998, p. 78): “el chiste es todo aquello que hábil y conscientemente hace surgir la comicidad, sea de idea o de la situación". Los chistes, según Freud (1905), se pueden construir con varios principios en los cuales el pensamiento queda reflejado en la frase o lo utilizamos de forma que decimos aquello que de otra manera no podríamos decir. De allí que la definición del chiste nos permite deducir varias cosas:

- Fenómeno psíquico

- Exclusivamente humano

- Verbal, juega con sonidos o palabras

- Intelectual, juega con las ideas

- Generador del placer de reír

La otra característica es lo breve que debe ser un chiste, ya que "la brevedad es el alma del ingenio" (Shakespeare 2005, p. 45), por lo tanto, mientras más corto sea este, la risa es más larga. En concordancia con lo anterior, y siguiendo en el desarrollo de las ideas con los ejemplos ya expuestos, utilizaremos ejemplos de humor escrito y verbal a través del chiste para relacionarlo con contenidos y situaciones de una clase de Educación para el trabajo, subárea: Agricultura. A continuación exponemos los siguientes:

- Había una vez un limón y un tomate que iban a cruzar la calle. El limón fue el primero en cruzar y de pronto un camión manejado por el Sr. Caimito lo atropelló. El tomate fue de emergencia a llevarlo al hospital más cercano. El tomate le pregunta al Dr. Manzano: - ¿Doctor, cómo está el limón? -El Dr. Manzano le responde: -Lamento decirle que su amigo el limón quedó en estado vegetal. (González, 2011, p. 35)

Este chiste se puede utilizar para desarrollar el contenido relacionado con la Botánica para explicar lo referente al reino vegetal.

En otro contenido se puede utilizar el siguiente chiste, citado por González (2011, p. 35), a manera de adivinanzas:

- ¿Cuál es el país con el suelo más infértil?

- -El Vaticano, que en 500 años solo ha dado 28 papas.

Este chiste permite abrir una discusión socializada en referencia a los suelos que presentan deficiencia de nutrientes (abonos).

Otro chiste que sirve para activar el proceso de enseñanza-aprendizaje en un contenido relacionado con siembra, tipos de siembra y densidad de siembra es el siguiente:

- Qué hace un agricultor en una finca corriendo y pegando gritos?

Sembrando el pánico. (González, 2010, p. 66) 
Los chistes que a continuación se mencionan pueden ser utilizados para establecer diferencias entre frutas originadas por semillas sexuales y asexuales:

- Esta era una fiesta exclusivamente de fresas, pero la piña tenía muchas ganas de ir. Cuando todas estaban en la fiesta llegó la piña y todas le preguntaron: - “que haces tú aquí?” y ella le contestó: - "es que vengo de piña colada”. (González, 2010, p. 66)

- Hay un montón de mangos en un ramo de un árbol y de repente uno se cae.

Todos los de arriba empiezan a reírse y a burlarse del que se ha caído y este responde:

-De qué se ríen... iInmaduros!-". (González, 2010, p. 66)

La idea es propiciar un aprendizaje en donde los estudiantes reconozcan que frutas como el mango, entre otras, se reproducen por semillas (vía sexual) y otras frutas como la fresa y la piña utilizan partes vegetativas para su reproducción (asexual).

Por otro lado, "existen otros momentos o situaciones espontáneas presentadas en el aula, que propician la creatividad humorística a través de una frase o un chiste (...)" (González, 2011, p. 35). A este tipo de situaciones espontáneas se le conoce como humor situacional, y es expuesto por Goodchilds (1972), Long y Graesser, (1988) y Mulkay, (1988) como aquel que se introduce de modo espontáneo en la conversación seria y que ha de ser interpretado a partir del contexto y de las circunstancias en las que tiene lugar. Otro autor, Fry (1963, p. 43) lo definió "como un tipo de humor espontáneo cuyo origen parte, en gran medida, de las relaciones interpersonales que se producen o establecen a lo largo de la conversación"5. Según estos autores, este tipo de textos carece de una fuerza humorística, y no formarían parte del mismo los chistes intencionales o planificados, las adivinanzas del tipo humorística, los juegos de palabras, entre otras alternativas, no obstante, estos géneros son en ciertos aspectos negociables en el marco de la conversación o de la clase. Con base en los argumentos anteriores, en el desarrollo de la estrategia de una clase pueden ocurrir situaciones espontáneas y cotidianas que originan la utilización de frases humorísticas, de acuerdo con situaciones surgidas y que ameritan el uso del humor situacional. Por ejemplo, cuando se está escribiendo en la pizarra y se rompe la tiza, espontáneamente puede surgir lo siguiente:

- "Creo que está tratando de escapar de mis manos" (la tiza)

- “Lo hice a propósito" (acompañado de un gesto). (González, 2011, p. 36)

Otro ejemplo, en donde se puede utilizar el humor situacional es cuando al docente se le hace difícil pronunciar una palabra. En este caso, en el desarrollo de la clase, González (2011, p. 36) pueden surgir las siguientes expresiones humorísticas:

- "Mi lengua se pegó al ojo de mi diente y no pude ver lo que estaba diciendo".

- "Esta mañana me lavé la boca y ahora no puedo moverla bien”.

\footnotetext{
Cita textual traducidas por el autor desde el inglés original.
} 
Puede suceder que el docente diga un chiste en la clase y este no logre su cometido (cause gracia) en los estudiantes. En este caso, se puede utilizar contrarréplicas con humor que ayudan, de manera estratégica, a solventar lo anterior. En el siguiente ejemplo se explican algunas contraréplicas humorísticas utilizadas en clases:

- "Es la última vez que le compro un chiste al profesor de Química, ya no causan risas”.

- "A mi hija de tres años le causó gracia".

- "Van a ver más tarde en el recreo o en su casa, se van a dar cuenta de lo gracioso que era y se van a morir de risa”. (González, 2011, p. 36)

Lo precedente conlleva a concluir, con Bourghiba (citado en González, 2011, p. 36), lo siguiente: "afortunado el hombre que se ríe de sí mismo, porque nunca le faltará motivos de diversión”. Entonces, si la diversión ayuda a hacer más efectiva una clase, se debería excluir cualquier aprendizaje que no fuese divertido.

\section{Consideraciones finales}

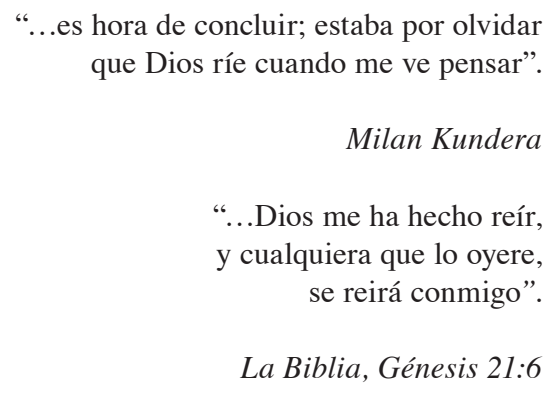

Concluir algo es muy difícil cuando lo que se quiere es abrir caminos para investigar la existencia. Decía Chillida (1994) en su discurso de ingreso en la Real Academia de Bellas Artes: "Yo no represento, ¿pregunto?" (párr. 60). Toda investigación es una pregunta, y esa pregunta me lleva a considerar como primera premisa que el humor ejerce una función pedagógica y didáctica dentro de la praxis pedagógica, ya que puede ser empleado en las diferentes materias que componen una determinada estructura curricular. Como segunda premisa, hay que introducir el humor en el verbo, ya que el humor, la sonrisa y la risa llevan implícito la comunicación, la cual puede utilizar el docente para hacer más dinámica una sesión de clases y romper las barreras de presión entre los estudiantes. Como tercera premisa, a veces un buen chiste puede ser una poderosa estrategia para ilustrar un determinado contenido en el aula, teniendo en cuenta, que no es preciso ser un humorista profesional para convertir en dinámica la praxis educativa. Si bien el humor como estrategia estimula el aprendizaje, hay que tener cuidado en la exageración, ya que se corre el riesgo de perder el objetivo de la clase, y la experiencia de aprendizaje se convierta en una simple sesión de entretenimiento. Finalmente, el tema deja una tarea de reflexión individual: el humor es la sonrisa del sentido y la razón, y de esas dos cualidades entre otras, está dotado el docente y sus estudiantes.

\footnotetext{
"...y si han aprendido de mí a reír, no es, sin embargo, mi risa la que han aprendido" 
"Se trata de un tema incompleto porque le falta respuesta; respuesta que alguno de ustedes [de la lista de referencias], quizás, le pueda dar".

Willy Colón. Canción “Oh, que será”.

\section{Referencias bibliográficas}

Acevedo, E. (1972). Los españolitos y el humor. Madrid: Editora Nacional.

Aristóteles. (1988). Poética (Ed. Trilingüe V. García Yebra). Madrid: Gredos.

Bergson, H. (1986). La risa (serie Austral). Madrid: Espasa Calpe.

Burguess, R. (2003). Escuelas que ríen. 149 3/4 propuestas para incluir el humor en las clases. Argentina: Troquel.

Carbelo, B. (2006). Estudio del sentido del humor. Validación de un instrumento para medir el sentido del humor, análisis del cuestionario y su relacón con el estrés (tesis doctoral). España, Universidad de Alcalá. Recuperado de http://dspace.uah.es/dspace/handle/10017/438

Checa F. (1992). El humor andaluz ¿identidad de un pueblo? Demófilo. Revista de cultura tradicional, 8, 55-84.

Chillida, E. (1994, 2 de marzo). Preguntas. (Discurso pronunciado con motivo de su investidura como doctor honoris causa por la Universidad de Alicante). Arvo.net Recuperado de http:// arvo.net/estetica/e-chillida-preguntas/gmx-niv593-con10133.htm

El Roto (Andrés Rábago). (2000).Viñeta El Roto. Tomado del diario El País (jueves 8 de jnio de 2000). Recuperado de http://zamorano37.blogspot.com/

Fernández, J. E. (2005). Guía práctica de risoterapia. Madrid: Orión Ediciones.

Flores, P. (2003). El humor gráfico en el aula de Matemáticas. Granada, Arial.

Fraguas-Forges, A. (s. f.). Cumbres. Recuperado de http://zamorano37.blogspot.com/

Freud, S. (1976/1905). El chiste y su relación con el subconsciente (Obras Completas Tomo VIII). Buenos Aires: Amorrortu editores.

Fry, W. (1963). Sweet Madness. A Study of Humor (2a ed.) [Locura dulce. Un estudio de humor] Palo Alto, USA: Pacific Books.

Garanto, J. (1983). Psicología del humor. Barcelona: Herder. 
González, F. (2009, octubre). Escuelas con humor. Revista Iberoamericana de Educación, 50(5), 1-6. Recuperado de www.rieoei.org/jano/3060GonalezJano.pdf

González, F. (2010). Pedagogía del humor: ¡Permitido reír! ¡Estamos en clases! (Colección: Jesús Rafael Zambrano). Venezuela: El perro y la rana.

González, F. (2011, febrero). Aplicación didáctica del humor pedagógico en el aula. Pedagogía magna, (12), 29-38. Recuperado de http://issuu.com/guiamundieduca/docs/pedagog a magna_n_mero_12

Goodchílds, J. D. (1972) On Being Witty: Causes, Correlates and Consequences [Sobre ser ingenioso: Causas, correlación y consecuencias]. En J.H. Goldstein y P.E. McGhee. The Psychology of Humor. Theoretical Perspectives and Empirical Issues (pp. 173-192). Nueva York: Academie Press.

Hobbes, T. (1993). Leviatán. Madrid: Editora Nacional.

Humor. Abogados americanos. Recuperado de http://www.proactiva-calidad.com/humor/ principal.html

Jankélévitch, V. (1983) La ironía. Madrid: Taurus.

Kant, I. (1981). Crítica del juicio (2 $2^{\mathrm{a}}$ ed.). Madrid: Espasa Calpe.

Larrosa, J. (2000). Elogio do riso [Elogio de la risa]. En J. Larrosa (Aut.). Pedagogia profana. Danças, piruetas e mascaradas (pp. 208-228). Belo Horizonte: Autèntica.

Lipps, T. (1998). Los fundamentos de la estética. Madrid: Daniel Jorro Editor.

Long, D. y Graesser, A. (1988). Wit and Humor in Discourse Processing. [El ingenio y el humor en el procesamiento del discurso]. Discouríe Processes. 11(1), 35-60. doi: $10.1080 / 01638538809544690$

Martin, R. (2003). Sense of humor [Sentido del Humor]. En S. López y C. R. Snyder (Eds.). Positive Psychological Assessment: A Handbook of Models and Measures [Evaluación positiva de Psicología: Un manual de modelos y medidas] (pp. 313-326). Washington DC: American Psychological Association.

Medina, L. (1992). Comunicación, humor e imagen. México: Trillas.

Mulkay, M. (1988). On Humor, its Nature and its Place in Modern Society. [Sobre el humor, su naturaleza y su lugar en la sociedad moderna]. Oxford: Basil Blackwell. 
Nietzsche, F. (1883 [1885]). Así habló Zarathustra. Barcelona: Orbis.

Perret, G. (1989). Using Humor for Effective Business Speaking [Utilización de humor para oratoria eficaz de negocio]. Nueva York: Sterling.

Pike, B. (1999). 101 Games for Trainers. [101 Juegos para entrenadores]. Estados Unidos de Norteamerica: Editorial Lakewood Publications.

Platón. (1992). Diálogos VI: Filebo, Timeo, Critias. (Trad., Introd. y Notas M. A. Durán y F. Lisi. Madrid: Gredos.

Schaeffer, N. (1981). The Art of Laughter. [El arte de la risa]. Nueva York: Columbia University Press.

Schopenhauer, A. (1996). El mundo como voluntad y representación. Barcelona: Editorial Planeta De Agostini.

Shakespeare, W. (2005). Hamlet (Colección libro de bolsillo). España. Editorial Alianza.

Singer, A. Viñeta Global Warming [Calentamiento Global]. (2009). Shred.com Recuperado de http://www.4shared.com/photo/BMfVKVB3/change - Andy singer - No Exit.htm

Snetsinger, W. y Grabowski, B. (1998). The Use of Humor in a CBI Science Lesson to Enhance Retention. [El uso del humor en una lección de Ciencia CBI para mejorar la retención]. Estados Unidos: Penn State University. Recuperada de ERIC (ED 373-764).

Spencer, H. (1860). The Physiology of Laughter. [La fisiología de la risa]. Mcmillan's Magazine, 1, 395-402.

Torres, H. (2006, enero-abril). Características personales del sentido del humor en áreas laborales. Telos, 8 (1), 122-128.

Vigara, A. M. (1994). El chiste y la comunicación lúdica: lenguaje y praxis. Madrid: Ediciones Libertarias. 